\title{
The Relationship of the Density and Consumption of Drilling Mud with a Model of Rock Drillability
}

\author{
Gulzhan Abdullaevna Kudaikulova ${ }^{1,}$, Boris Vladimirovich Fedorov, \\ Aizada Baltagalievna Sharauova ${ }^{2}$ \\ ${ }^{1}$ Limited Liability Partnership (LLP) "Burmash", Almaty, Kazakhstan \\ ${ }^{2}$ Department Geology and Oil-Gas Business, Kazakh National Technical University, Almaty, Kazakhstan
}

\section{Email address:}

kgulzhanabd@mail.ru (G. A. Kudaikulova), burmash@mail.ru (G. A. Kudaikulova), fedorovbv2017@mail.ru (B. V. Fedorov), aizada_0590@mail.ru (A. B. Shrauova)

${ }^{*}$ Corresponding author

\section{To cite this article:}

Gulzhan Abdullaevna Kudaikulova, Boris Vladimirovich Fedorov, Aizada Baltagalievna Sharauova. The Relationship of the Density and Consumption of Drilling Mud with a Model of Rock Drillability. American Journal of Engineering and Technology Management. Vol. 4, No. 1, 2019, pp. 5-9. doi: 10.11648/j.ajetm.20190401.12

Received: January 11, 2019; Accepted: March 13, 2019; Published: April 9, 2019

\begin{abstract}
In article it is shown the functional connection between the drillability model and the required consumption of drilling mud for cleaning the bottom of a well from destruction products. In particular, it has been shown that when drilling oilgas wells in uncomplicated conditions, the required consumption of drilling mud is directly proportional to the current drilling speed and increases in quadratic dependence on the diameter of the well. It was found that the increase in the density of drilling mud due to contamination with drill cuttings at the revelation of "weak" formations has the greatest influence, which in certain conditions can cause hydraulic fracturing of the formation. At the revelation of formations with abnormally high pressure, an increase in the density of the contaminated drilling mud has practically not influence on the prevention of kicks.
\end{abstract}

Keywords: Model of Drillability, Speed of Drilling, Density of Mud, Consumption of Mud, Contamination, Hydraulic Fracturing, Kick

\section{Introduction}

The model drillability represents mathematical dependence of interaction a bit with bottom well in time during end of the run. Usually, this formula includes the initial speed of the drilling $\vartheta_{0}$ the new unworn rock cutting tool, the coefficient to characterizing the speed of wear of a bit and time of drilling t.

It is possible to give widely known model of drilling for roller bit as an example [1]:

$$
(t)=\vartheta_{0} \exp (-k t)
$$

Researchers Bourgoyne and Young developed model of drillability [2] in which the speed of drilling is presented by also exponential, but more difficult dependence. In the exponent index there are included 8 parameters which influence on a drilling speed. This model found application at percussion-rotary drilling with use of roller bits.
The model drillability offered Maurer [3] is also intended in case use of roller bits. Authors of works [4-7] offer model of drillability which is described by the following equation:

$$
(t)=\vartheta_{0}-\Delta \vartheta t^{m}
$$

where $\vartheta_{0}$ - the initial speed of drilling by the rock cutting tool with the new unworn bit at the rational technological mode;

$\Delta \vartheta$ - the rate of reduction of speed drilling caused by abrasive wear of arms of the tool;

$t$ - the considered drilling time;

$m$ - an exponent in which time is built, and characterizing reduction of speed $\vartheta(t)$ (with accrued or decreasing reduction in the rate of drilling).

In figure 1. this dependence is presented.

In our opinion, the offered model of drillability displays rather sufficient universality and contains three constants of identification $\left(\vartheta_{0}, \Delta \vartheta, m\right)$. The last one indirectly consider 
influence of parameters mode of drilling and design features of bit on drillability of rocks.

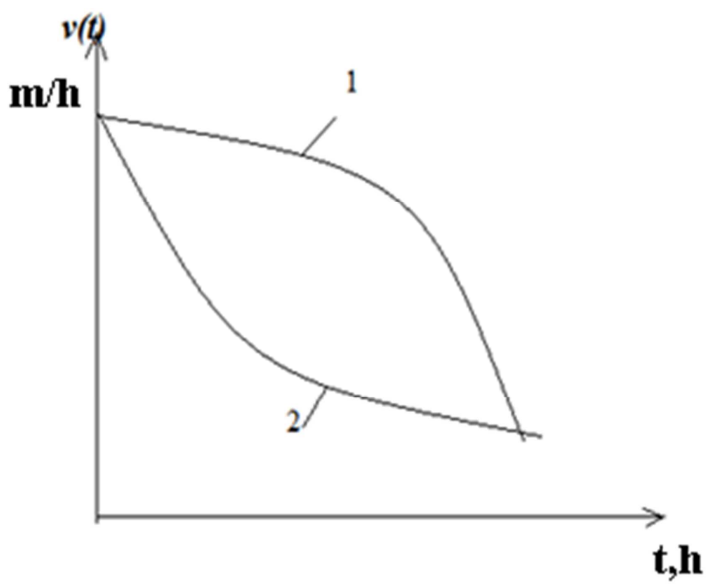

Figure 1. Change of drilling speed $\vartheta(t)$ in the homogeneous rock: 1 increasing decrease of speed $\vartheta(t) ; 2$ - reducing decrease of speed $\vartheta(t)$.

In formulas $(1,2)$ the initial speed of drilling $\vartheta_{0}$ is defined experimentally or analytically, and, as a rule, for its definition the following parameters of the technological mode are used: axial load on a bit $G$ and frequency rotation of bit $n$.

Often mathematical dependence $\vartheta_{0}=f(G, n)$ recognized as a drillability model that is incorrect because in this case it is not considered an wear of bit in the process of run.

Never the less, scientists of the different countries offered several tens of formulas for definition $\vartheta_{0}$ in which features drilling method, constructions of the rock cutting tool, physic-mechanical properties of rocks and other indicators are considered [8].

Let's give the formula for the initial speed of drilling received by us for $\mathrm{PDC}$ bits taking into account their rotation by the screw engine [9]:

$$
\vartheta_{0}=\frac{k_{0} n G}{k_{1} P_{h} R_{d}}
$$

where $k_{0}=\frac{f \cos \alpha-\sin \alpha}{f 0.62 \operatorname{tg} \alpha}(f-$ friction coefficient on contact a cutter - rock of bottom,

$\alpha$ - angle between the plane of a cutter of PDC and vertical);

$k_{1}$ - the coefficient considering installation of diamond hard-alloy plates on matrix of bit having gaps between cutters;

$n$ - frequency rotation of bit, $1 / \mathrm{s}$;

$G$ - axial load on a bit, N;

$P_{h}-$ the hardness of rock, $\mathrm{Pa}$;

$P_{d}-$ bit radius, $\mathrm{m}$.

Thus, the analysis of the existing models of drillability shows that they do not consider one main technological parameter of drilling process - flashing of the well in the process of deepening bottom and together with it such important technological properties of drilling mud as density and consumption.

\section{Methods}

In article the following methods of researches are used:

(a) the literary review of the existing models of drillability and their fields of using;

(b) mathematical analysis of dependences of drilling parameters and establishment of functional dependences of speed drilling and consumption of drilling mud;

(c) experimental researches of influence of technological parameters of the mode of drilling on well-drilling productivity RDS bits on the Uzen deposit of Kazakhstan.

\section{Discussion}

The consumption and density of the drilling mud for flushing the well depends on the intended purpose of well and mainly on the degree of stability of the rocks penetrated by the well, the presence of high pressure formations in the section or weak formations that are prone to hydraulic fracturing. Such drilling muds indexes as viscosity, water loss, static shear stress and others influence on a trouble-free drilling in difficult conditions. The value of consumption drilling mud should ensure the purity of the formed bottom and the complete removal of the products of the destroyed rock (drill cuttings) to the surface.

It follows that the value of consumption drilling mud is connect to the drilling speed, i.e. with the speed of formation of cuttings at the bottom of the well.

We will identify the mentioned connection initially in the simpler case, when there are no high-pressure formations or "weak" formations that are prone to hydraulic fracturing and drilling mud loss. Also, the situation is often observed at drilling for hard rocks, when drilling wells are being drilled in dense igneous or metamorphic rocks.

For the solution this problem we used the dependence (2).

In the case of drilling of rocks intermittence on hardness, the speed function $\vartheta(t)$ at the place of transition of some rocks to others (Figure 2) will have discontinuities (jumps) in the direction of increasing or decreasing speed of drilling.

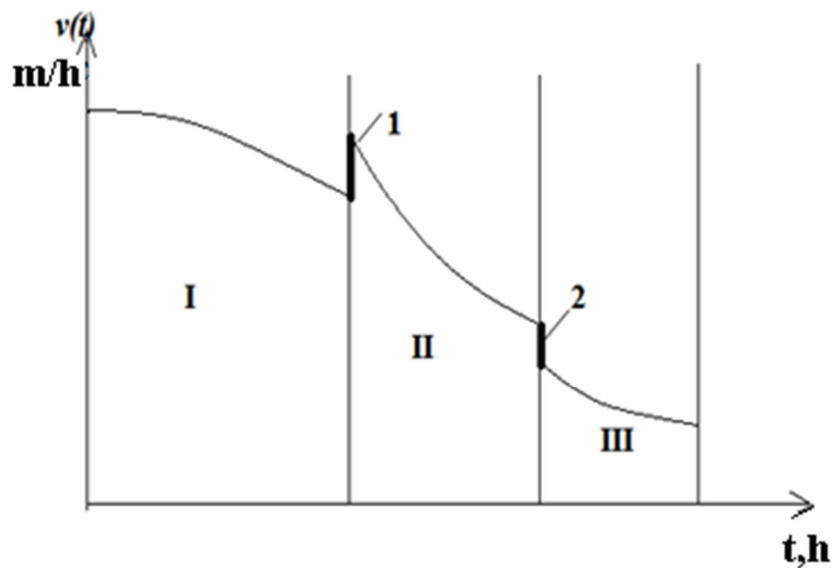

Figure 2. Change of drilling speed $\vartheta(t)$ in rocks intermittence on hardness: I-primary rock; II - rock of lower hardness; III - rock of greater hardness. 
The volume of the destroyed rock (cuttings) $V_{d r}$ depends on the drilling speed $\vartheta(t)$ and will be equal to:

$$
V_{d r}=\vartheta(t) \frac{\pi D_{c}^{2}}{4}
$$

Where $D_{c}$ - diameter of the well.

With the destruction of bottom the drilling mud is more or less contaminated with cuttings. The degree of contamination $\alpha$ of drilling mud at the drilling speed $\vartheta(t)$ will be:

$$
\alpha=1-\frac{Q}{\vartheta(t) \frac{\pi D_{C}^{2}}{4}+Q}=1-\varphi
$$

where $Q$ - consumption of drilling mud, calculated by rational drilling technology;

$\varphi$ - fluid content in the cuttings-fluid flow.

In accordance with the technology of rotary drilling for the implementation of high-quality bottom mud flushing, the density of the reverse, enriched by cuttings, fluid flow according to the degree of contamination should not exceed $3 \%$, i.e. $\alpha \leq 0.03$ [10]. Substituting the last value $\alpha$ into equation (5) and resolving it relative to $Q$, we obtain the required minimum consumption of drilling mud, with the maximum allowable concentration of cuttings:

$$
Q \approx 25 \vartheta(t) D_{c}^{2}
$$

From the analysis of the obtained dependence (6) it follows that the consumption of drilling mud increases in direct proportion to the speed of drilling and in quadratic dependence on the diameter of the well.

Usually with a rational flushing mode, the degree of contamination of mud is not brought to the limit, drilling is carried out at $\alpha_{p}=0.01$, even at a high speed of destruction of the bottom. Substituting this value $\alpha_{\mathrm{p}}$ in (6), we obtained the necessary consumption mud:

$$
Q=77,7 \vartheta(t) D_{c}^{2}
$$

Let us verify the correctness of the above formula in practice when drilling oil-gas wells in the large Kazakhstan deposit Uzen [6]. Drilling under the operating string is carried out with the PDC 220 bit in the interval 200 - (1100$1300 \mathrm{~m})$. The initial speed with new, unworn bit is $18.5-20$ $\mathrm{m} / \mathrm{h}(0.051-0.055 \mathrm{dm} / \mathrm{s})$.

Substituting $v_{0}=0.051 \mathrm{dm} / \mathrm{s}$ and $D_{c}=2.2 \mathrm{dm}$ in (5), we obtain the initial consumption of mud equal to:

$$
Q_{\mathrm{H}}=77,7 * 0,051 * 2,2^{2}=19,20 \mathrm{l} / \mathrm{s} \approx 1150 \mathrm{l} / \mathrm{min}
$$

as whole, it is confirmed by a mode - technological map.

However, by the end of drilling in the first well under the operating string, the drilling speed declined to $14.5 \mathrm{~m} / \mathrm{h}$ $(0.049 \mathrm{~m} / \mathrm{s})$; as a result of abrasive wear of the PDC 220 bit. Therefore, in the absence of possible complications, the necessary consumption of mud at the end of run will be:

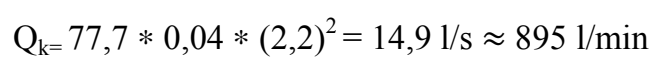

Statistical processing of chronometrical data [6] resulted a mathematical model of the process when drilling with the bit of first group wells, which included data on the results of drilling the interval under the operating string with bits of new, unworn matrix. This model after determining the constants $\vartheta_{0}, \vartheta(t)$ and $m$ in the formula (2) looks as follows:

$$
\vartheta(t)=18,5-0,143 t^{0,8}
$$

Consequently, with a decrease of drilling speed, it is necessary to reduce the consumption of drilling mud accordingly, while the degree contamination of mud by cutting (in this example $\alpha=0.01$ ).

Thus, in uncomplicated conditions, the consumption of drilling mud when it is associated with the drilling speed, should repeat the relationship shown in Figure 1, 2.

Consider further difficult mining-geological conditions, which including drilling formations with abnormally high pressure and weak formations with risk of hydraulic fracturing under the pressure of drilling mud.

The conditions for creating the necessary backpressure on a high-pressure reservoir are follows [11]:

$$
\rho=\min \left\{\frac{\mathrm{P} p l k_{r}}{g L_{K}} ; \frac{P p l+\Delta P_{P}}{g L_{K}}\right\}
$$

where $\rho$ - density of drilling fmud ;

$\kappa_{r}-$ reserve coefficient, the value of which varies from 1.04 to 1.15 (depending on the

depth $L_{k}$ of the roof of the reservoir);

$P_{p l}$ - reservoir pressure;

$\Delta P_{p}$ - well pressure over reservoir pressure.

$\Delta P_{P}=1.5 \div 3.5 \mathrm{MPa}$ (depending on the value of $L_{k}$ );

$g$ - gravitational acceleration

We give an estimate of the change density of drilling mud enriched by drilling cuttings and exerting pressure on the high-pressure formation.

The volume of the destroyed rock $V_{d r}$ on the bottom of well at drilling speed during the time $d t$ will be:

$$
V_{d r}=v d t S=v d t \frac{\pi}{4} D_{c}^{2}
$$

During the $d t$ time on bottom entry the volume of drilling mud will be equal to

$$
V_{d m}=Q d t
$$

where $Q$ - consumption of drilling mud

The corresponding masses of the destroyed rock $M_{d r}$ and $M_{d m}$ drilling mud are equal to:

$$
\begin{gathered}
\mathrm{M}_{d r}=\rho_{d r} V_{d r}=\rho_{d r} \vartheta d t \frac{\pi}{4} D_{c}^{2} \\
\mathrm{M}_{d m}=\rho_{d m} V_{d m}=\rho_{d m} Q d t
\end{gathered}
$$

In dependencies (12), (13) $\rho_{d r}, \rho_{d m}$ - respectively the densities of destroyed rock and drilling mud.

So the total amount of destroyed rock and drilling mud is $V_{\text {total }}=V_{d r}+V_{d m}$ and their total mass is $M_{\text {tot }}=M_{d r}+M_{d m}$, then the density of mud polluted with drilling cuttings $\rho_{p m}$ will be: 


$$
\rho_{p m}=\frac{\mathrm{M}_{t o t}}{V_{t o t}}=\frac{\rho_{d r} \vartheta \frac{\pi}{4} D_{c}^{2}+\rho_{d m} Q}{\vartheta \frac{\pi}{4} D_{c}^{2}+Q}
$$

\section{Results}

Let us estimate the degree of the influence of contamination of mud on its density at a high drilling speed with the following data:

$$
\begin{gathered}
\rho_{d r}=2500 \frac{\mathrm{kg}}{\mathrm{m}^{3}} ; \vartheta=20 \frac{\mathrm{m}}{\mathrm{h}}\left(0,0055 \frac{\mathrm{m}}{\mathrm{s}}\right) \\
D_{c}=220 \mathrm{~mm}(0,22 \mathrm{~m}) \\
\rho_{d m}=1200 \frac{\mathrm{kg}}{\mathrm{m}^{3}} ; \mathrm{Q}=201 / \mathrm{s}\left(0,02 \frac{\mathrm{m}^{3}}{\mathrm{~s}}\right)
\end{gathered}
$$

Substituting these data into (10), we get:

$$
\begin{gathered}
\rho_{p m}=\frac{2500 * 00055 * \frac{3,14}{4}(0,22)^{2}+1200 * 0,02,}{0,0055 * \frac{3,14}{4}(0,22)^{2}+0,02} \\
=1214 \frac{\mathrm{kg}}{\mathrm{m}^{3}}
\end{gathered}
$$

It follows that an increase of the density of the contaminated mud, even at a high drilling speed, is about $1 \%$ of the density of the uncontaminated mud. Therefore, such a small increase in density cannot influence the prevention of water-oil seep. Such and much more significant fluctuations in the density of mud are taken into account by the reserve coefficient $K_{r}$, which is included in the dependence (9).

A greater effect is exerted by an increase of the density of the contaminated solution upon contact with a weak formation, which may cause its hydraulic fracturing and drilling mud loss. The corresponding density of the mud must be checked according to the second condition - the pressure of the drilling mud in the annulus against each reservoir must be less than the pressure necessary to fracture the reservoir. Since the pressure in the well is connected with density of mud, the above condition can be written as the following equation [11]:

$$
\rho_{c d}<\frac{\mathrm{P}_{\mathrm{f}}-\sum\left(\Delta \mathrm{P}_{l b}\right)-(1-\varphi) \rho_{r} g L_{b}}{\varphi g L_{b}}
$$

where $\rho_{c d}$ is the critical density of the solution at which a hydraulic fracturing occurs;

$P_{f}$ - hydraulic fracturing pressure;

$\sum\left(\Delta \mathrm{P}_{l b}\right)$ - pressure loss during flow of drilling mud in the annulus on the way from the bottom of considered formation to the wellhead;

$L_{b}$ - the depth of the bottom of the reservoir in question to the mouth;

$\rho_{r}-$ the density of drilled rocks.

Analysis of equation (15) shows that the critical density of the mud $\rho_{c d}$, at which hydraulic fracturing can occur, depends on the ratio of the following values: $\varphi, L_{b}, \rho_{r}, \mathrm{P}_{f}$ and $\sum\left(\Delta \mathrm{P}_{l b}\right)$.

Let us explain this position with the data from the following example: $P_{f}=35 \mathrm{MPa} ; \varphi=0.97 ; L_{b}=2450 \mathrm{~m} ; \rho_{r}=$ $2400 \mathrm{~kg} / \mathrm{m}^{3} ; \sum\left(\Delta \mathrm{P}_{l b}\right)=5.0 \mathrm{MPa}$; the density of the applied drilling mud $\rho_{c d}=1300 \mathrm{~kg} / \mathrm{m}^{3}$.

Calculate the value of $\rho_{c r}$ by the formula (15) at degree of contamination $\varphi=0.97$ and $\varphi=0.99$ :

$$
\begin{gathered}
\rho_{1}=\frac{35 * 10^{6}-5 * 10^{6}-(1-0,97) 2400 * 9,81 * 2450}{0,97 * 9,81 * 2450}=1212 \frac{\mathrm{kg}}{\mathrm{m}^{3}} \\
(\varphi=0,97) \\
\rho_{2}=\frac{35 * 10^{6}-5 * 10^{6}-(1-0,99) 2400 * 9,81 * 2450}{0,99 * 9,81 * 2450}=1262 \frac{\mathrm{kg}}{\mathrm{m}^{3}} \\
(\varphi=0,99)
\end{gathered}
$$

Thus, in both cases, hydraulic fracturing will not occur, because the drilling mud has a value of $\rho_{c d}=1300 \mathrm{~kg} / \mathrm{m}^{3}$, which is more than the calculated values of $\rho_{1}$ and $\rho_{2}$, however, when contaminated $\rho_{2}=1262 \mathrm{~kg} / \mathrm{m}^{3}$, the density approaches the critical density at which there will be hydraulic fracturing.

\section{Conclusions}

1. In uncomplicated geological conditions, the required consumption of drilling mud for cleaning the bottom of well increases in quadratic dependence on the diameter of the well and is directly proportional to the speed of drilling.

2. Due to the abrasive wear of the rock cutting tool, the drilling speed is reduced in accordance with the process model. It is recommended to create equipment with which it will be possible to regulate the rational consumption of the mud in accordance with the change in the speed of destruction of the bottom and a decrease in the amount of cuttings formed.

3. The increasing density of the cuttings-fluid flow in the annulus has practically no noticeable influence on the prevention of kick from high-pressure formations.

4. A more noticeable influence is the speed of drilling. The increasing density of the cutting-fluid flow in this connection increases the hydrostatic pressure on the weak formations, which can cause their fracturing and drilling mud loss. In these conditions it is necessary an appropriate calculation taking into account the actual drilling speed and the pressure of the cutting-fluid flow on the weak formation.

\section{References}

[1] A. G. Kalinin, A. S. Oganov, A. A. Sazonov, S. N. Bastrikov. Construction of oil and gas wells. M: Print center of Gubkin Russian State University of Oil and Gas., 2013, 690 P.

[2] Bourgoyne A. T., Young F. S. A Multiple Regression Approach to optimal drilling and abnormal pressure detection. SPE 4238, August 1974.

[3] Maurer W. C. The perfect-cleaning theory of rotary drilling. Journal of Pet. Tech. 2000, November.

[4] Levitsky A. Z. The use of geology technical information in the drilling. Moscow, Nedra, 1992. 
[5] B. V. Fedorov, M. T. Aubakirov, A. B. Sharauova. About the model of drillability of oil and gas wells with PDC bits at the Uzen. Vestnik KazNRTU, vol. 1, 2017, p. 84-90

[6] B. V. Fedorov, B. Ratov, A. B. Sharauova. Development of the PDC bits for Uzen oilfield (the Republic of Kazakhstan). East European Journal of Advanced Technology. Engineering technological systems. 3/1 (87) 2017, p. 16-23.

[7] Levitsky A. Z. Use of data of geological and technical control for optimization of drilling. M: VNIIOENG, 1987, 37 P.
[8] Sinev S. V. Models of drilling process. Oil and gas business, 2009. http://www.ogbus.ru

[9] Fedorov B. V., Huzina A. B., Ratov B. T., Sharauova A. B. Modeling of process of deepening of wells PDC chisels. Oil and gas, No. 4 (100), 2017., p. 77-85, Almaty.

[10] N. D. Mikhailova Technical design of core drilling M: Nedra, 1995, 197 P.

[11] E. G. Leonov, V. I. Isaev, Hydro-aeromechanics in drilling. M: Nedra, 1987, p. 123-125. 